\title{
Soldering of non-wettable Al electrode using Au-based solder
}

\author{
Fengqun Lang $\cdot$ Hiroshi Nakagawa $\cdot$ Hiroshi Yamaguchi
}

Published online: 12 December 2013

(C) The Author(s) 2013. This article is published with open access at Springerlink.com

\begin{abstract}
In manufacturing three-dimensional $\mathrm{SiC}$ power modules, the $\mathrm{Al}$ electrode of $\mathrm{SiC}$ power devices should be soldered to the substrate. However, the Al electrode is difficult to be bonded by a solder due to the naturally formed aluminum oxide on it. In this paper, we describe an effective approach for soldering the non-wettable Al electrode by fabricating a $\mathrm{Au}$-stud bump in the $\mathrm{Al}$ electrode together with a Au-20 wt $\%$ Sn or Au-12 wt $\%$ Ge solder. The soldering initiated at the Au bump and spreaded on the $\mathrm{Al}$ electrode. The soldering featured as reactive wetting, realized by the reaction of liquid $\mathrm{Au}$ in the $\mathrm{Au}$-base solder and the $\mathrm{Al}$ electrode. The activation energy of the Au- $20 \mathrm{wt} \% \mathrm{Sn}$ soldering the $\mathrm{Al}$ electrode was $Q=159 \mathrm{~kJ} / \mathrm{mol}$. A continuous $\mathrm{Au}_{4} \mathrm{Al}$ layer formed at the $\mathrm{Au}-20 \mathrm{wt} \% \mathrm{Sn}$ bond interface. The shear strength exceeded $60 \mathrm{MPa}, \sim 1$ order magnitude higher than the required shear strength. For the bond with $\mathrm{Au}-12 \mathrm{wt} \% \mathrm{Ge}$ solder on the $\mathrm{Al}$ electrode with a Au bump, the liquid Au$12 \mathrm{wt} \%$ Ge solder reacted with the solid $\mathrm{Al}$ electrode and formed a Au-Ge-Al solid solution after solidification. The shear strength of the Au- $12 \mathrm{wt} \%$ Ge solder on the Al electrode with a Au bump was beyond $50 \mathrm{MPa}$. Little electrical characteristics of the SiC-SBD changed after the Al electrode was bonded to a circuit substrate using this technology.
\end{abstract}

Keywords Au-Sn alloy · Au-Ge alloy · Wetting · Soldering · Aluminum electrode $\cdot$ Metallization

F. Lang $(\bowtie) \cdot$ H. Nakagawa $\cdot$ H. Yamaguchi

Advanced Power Electronics Research Center, National Institute of

Advanced Industrial Science and Technology (AIST),

Tsukuba 305-8568, Japan

e-mail: fqlang03325@yahoo.co.jp

Present Address:

F. Lang

R \& D Partnership for Future Power Electronics Technology, c/o,

AIST, Tsukuba, Japan

\section{Introduction}

Development of the next-generation energy-saving and miniaturized power converters using the newly developed lowpower conversion loss and high-temperature resistant $\mathrm{SiC}$ power devices is under way worldwide [1]. The $\mathrm{SiC}$ power devices can operate above $200{ }^{\circ} \mathrm{C}$ and can withstand reflow temperature of $500{ }^{\circ} \mathrm{C}[2]$. The upside electrodes of almost all the $\mathrm{SiC}$ and $\mathrm{Si}$ power devices are metalized with $\mathrm{Al}$ or its alloys for its desirable properties such as ease of patternability, high conductivity, and good adherence [3, 4]. At present, twodimensional (2-D) fabrication technology is the mainstream in power electronics manufacture with Si power devices. The $\mathrm{Al}$ electrodes are connected to the electrode in the substrate or other devices with $\mathrm{Al}$ or Au wires using ultrasonic energy and a pressure $[3,5,6]$. There are urgent requirements of miniaturized power modules. Three-dimensional (3-D) integration of power modules using $\mathrm{SiC}$ power devices makes it possible to miniaturize the volume of power modules by providing double-side heat dissipation and reducing electrical noise [7, 8]. In fabricating a 3-D power module, the upper and lower side electrodes of power devices should be soldered to the substrates. However, Al is very reactive with atmospheric oxygen, and a thin and chemically stable $\mathrm{Al}$ oxide film ( $\sim 4 \mathrm{~nm}$ thickness) immediately forms on any exposed aluminum surface $[9,10]$. This aluminum oxide film hinders the bonding of a solder to the $\mathrm{Al}$ electrode.

Although solderablity of the Al electrode can be realized by photolithography wafer process combined with electroplating, evaporation, zincate pretreatment, and $\mathrm{Ni}$ electroless deposition followed by $\mathrm{Au}$ electroless plating, single chip with $\mathrm{Al}$ electrode is unsuitable $[11,12]$. Further, the process is complex and cost-ineffective. It is difficult to apply electroplating or electroless plating process or physical vapor deposition to deposit solderable metal pads on single chip. However, most of the devices are supplied as discrete chips. The 
Sn3.5Ag4Ti(Ce,Ca) with a melting point (M.P) of $~ 220{ }^{\circ} \mathrm{C}$ has ever been reported to be able to solder $\mathrm{Al}$ alloys $[13,14]$. The soldering temperature above $800^{\circ} \mathrm{C}$ is so high that could damage the $\mathrm{SiC}$ power devices and exceeds the M.P of the $\mathrm{Ag}-\mathrm{Cu}-\mathrm{Ti}$ bond for the $\mathrm{Cu}$ pattern layer on the ceramic substrate. Further, the M.P of this solder is too low to endure the operation temperature above $200{ }^{\circ} \mathrm{C}$. Sn-3.5Ag- $x$ Ti was used to bond the $\mathrm{Al}$ alloys at $250{ }^{\circ} \mathrm{C}$. But a two-step soldering process is needed by brushing the bonded solder pad formed in the first step soldering. Sn- $x \mathrm{Zn}$ solders (M.P $=198.5^{\circ} \mathrm{C}$ ) have ever been reported to be able to bond the $\mathrm{Al}$ alloys [15-17]. The M.P of all these solders is too low to be used in high temperature electronics $\left(>200{ }^{\circ} \mathrm{C}\right) . \mathrm{Au}-20 \mathrm{wt} \% \mathrm{Sn}$ eutectic solder (M.P $=278{ }^{\circ} \mathrm{C}$ ) and $\mathrm{Au}-12 \mathrm{wt} \%$ Ge eutectic solder (M.P $=356{ }^{\circ} \mathrm{C}$ ) are extensively used in high-power electronics and optoelectronics packaging. These Au-based solders feature as good mechanical properties, high electrical and thermal conductivity along with excellent corrosion resistance $[18,19]$. In this paper, we describe a new method for soldering an $\mathrm{Al}$ electrode using Au-based solders together with fabricating a tinny Au bump ( $~ 80 \mu \mathrm{m}$ diameter $)$ in the $\mathrm{Al}$ electrode. The reactive wetting between the Au-based solders and the $\mathrm{Al}$ electrode, the wetting rate, the active energy of the reactive wetting, and the bond strength were investigated.

\section{Experimental procedures}

SiC Schottky Barrier Diode (SBD) power device (reverse voltage 1,200 V; continuous current $20 \mathrm{~A}$ ) chips with an $\mathrm{Al}$ upside electrode (anode) were used in this experiment. The $\mathrm{Al}$ electrode has an area of $2.13 \mathrm{~L} \times 2.13 \mathrm{~W}\left(\mathrm{~mm}^{2}\right)$ and a thickness of $4 \mu \mathrm{m}$. Beneath the $\mathrm{Al}$ electrode is a thin tungsten (W) layer. A $25-\mu \mathrm{m}$-diameter $\mathrm{Au}-1 \mathrm{wt} \% \mathrm{Pd}$ wire was used to form the $\mathrm{Au}$ bumps in the $\mathrm{Al}$ electrode using a Au stud bump bonder (model, SBB-1, Shinkawa Co., Ltd, Japan). The Au stud bumps were prepared with a forming voltage of 2,200 V and a current of $4 \mathrm{~mA}$ at $300{ }^{\circ} \mathrm{C}$ in air. The Au bump had a base diameter of $82 \mu \mathrm{m}$. Since the surficial status of the Al electrode has strong influence on the spreading behavior of a liquid alloy [20], the $\mathrm{Al}$ electrode without heavy scratches were used.

Solder pastes are commonly used in electronics manufacturing for their flexibility in bonding pads with different sizes and configurations, in addition to the surface cleaning effect of the mixed flux. The Au- $20 \mathrm{wt} \% \mathrm{Sn}$ (M.P, $278{ }^{\circ} \mathrm{C}$, hereafter denoted as $\mathrm{Au}-20 \mathrm{Sn}$ ) eutectic solder paste was used to bond the Au-bumped $\mathrm{Al}$ electrode in this research work. The Au-20Sn solder paste contains $\mathrm{Au}-20 \mathrm{Sn}$ particles with diameters $<32 \mu \mathrm{m}$. The Au-20Sn paste was dispensed on the Au-bumped Al electrode of SiC-SBD. Then, the SiC-SBD device was placed in a reflow analyzer system (Model:VISTA
7, Okuhara Electric Cop., Japan; maximum reflow temperature, $350{ }^{\circ} \mathrm{C}$ ). The reflow was performed in $\mathrm{N}_{2}$ atmosphere (oxygen content $<16 \mathrm{ppm}$ ). The ramp-up rate from soak temperature to reflow temperature was $1{ }^{\circ} \mathrm{C} / \mathrm{s}$. The cooling rate after reflow was $\sim 3{ }^{\circ} \mathrm{C} / \mathrm{s}$. The reflow temperature was set to be $300,320,330$, and $340^{\circ} \mathrm{C}$, respectively. Four milligrams solder paste was used for each reflow temperature. The images of the solder ball were recorded by a CCD camera during reflow. The area of the image of the solder ball was measured using Bersoft Image Measurement software. The radius of the image was calculated from the measured area. The bond strength of the solder to the $\mathrm{Al}$ electrode was measured using a die shear tester (Model 4000, Dage Holdings, Ltd., UK). The tests were carried out at room temperature with a displacement rate of $150 \mu \mathrm{m} / \mathrm{s}$. To investigate the cross-sectional microstructure of the bond of the solder on the Al electrode, some of the soldered specimens were fractured. The microstructure of the specimens was also observed and analyzed with the scanning electron microscope (SEM, LEO/EEiSS GEMINI FESEM, Model Supra 35, Carl Zeiss SMT Ltd., Germany) equipped with an energy dispersed X-ray analyzer (EDX, Genisis Spectrum, Model LEO 35, EDXA Ltd., USA).

For comparison, the $\mathrm{Pb}-10 \mathrm{wt} \% \mathrm{Sn}$ high temperature solder paste (solidus temperature, $275{ }^{\circ} \mathrm{C}$; hereafter termed as $\mathrm{Pb}$ $10 \mathrm{Sn})$ and $\mathrm{Sn}-3 \mathrm{Ag}-0.5 \mathrm{Cu}(\mathrm{wt} \%)$ eutectic solder paste (M.P, $217^{\circ} \mathrm{C}$; hereafter termed as $\mathrm{Sn} 3 \mathrm{Ag} 0.5 \mathrm{Cu}$ ) were used to solder the single Au-bumped Al electrode (hereafter denoted as SABA), respectively. The reflow was carried out with the reflow analyzer system. The reflow peak temperature and time for $\mathrm{Pb}-10 \mathrm{Sn}$ and $\mathrm{Sn}-3 \mathrm{Ag}-0.5 \mathrm{Cu}$ were $350^{\circ} \mathrm{C}$ for $200 \mathrm{~s}$ and $250{ }^{\circ} \mathrm{C}$ for $200 \mathrm{~s}$, respectively.

The Au-bumped Al electrode was also bonded using a high temperature solder $\mathrm{Au}-12 \mathrm{wt} \%$ Ge eutectic solder paste (M.P, $356{ }^{\circ} \mathrm{C}$; hereafter denoted as Au-12Ge). This paste contains $\mathrm{Au}-12 \mathrm{Ge}$ alloy particles with diameters $<32 \mu \mathrm{m}$. The reflow process was carried out at $430{ }^{\circ} \mathrm{C}$ for $180 \mathrm{~s}$ with a high temperature vacuum reflow system (Model SRO-704, ATV Technology $\mathrm{GmbH}$, Germany; maximum reflow temperature, $500{ }^{\circ} \mathrm{C}$ ). The SiC-SBDs with the SABA were bonded to a $\mathrm{Cu} / \mathrm{Ni}(\mathrm{P})$ metalized $\mathrm{Si}_{3} \mathrm{~N}_{4}$ substrate with the Au-12Ge solder paste in a $\mathrm{N}_{2}$ atmosphere. The shear strength of the bond was tested at room temperature. The cross sections of the bond were observed and analyzed with SEM/EDX.

In order to investigate the alloying effect of the Au-based solders with the $\mathrm{Al}$ electrode, $\mathrm{Au}-20 \mathrm{Sn}$ and $\mathrm{Au}-12 \mathrm{Ge}$ solder sheets were used to bond the SABA by a reflow process without flux. The reflow was performed in the vacuum reflow system. The reflow was conducted at $350{ }^{\circ} \mathrm{C}$ for $120 \mathrm{~s}$ and $430{ }^{\circ} \mathrm{C}$ for $120 \mathrm{~s}$ for the $\mathrm{Au}-20 \mathrm{Sn}$ solder and $\mathrm{Au}-12 \mathrm{Ge}$ solder sheets, respectively. The surficial and fracture morphologies after reflow or after shear test were investigated with SEM/EDX. 
To evaluate the electrical characteristics of the SiC-SBD after its SABA was bonded to a $\mathrm{Cu}(300 \mu \mathrm{m}) / \mathrm{Ni}(\mathrm{P})(5 \mu \mathrm{m}) / \mathrm{Au}$ $(0.05 \mu \mathrm{m})$-metalized $\mathrm{Si}_{3} \mathrm{~N}_{4}(320 \mu \mathrm{m})$ ceramic substrate (the value in the parenthesis represents the thickness), the forward current-forward voltage $\left(I_{\mathrm{F}}-V_{\mathrm{F}}\right)$ curves and reverse currentreverse voltage $\left(I_{\mathrm{R}}-V_{\mathrm{R}}\right)$ curves were measured with a highpower curve tracer (model, 371A, Tektronix, Inc., USA). To protect the guard ring on the periphery of the anode of the SiC$\mathrm{SBD}$, the SABA was bonded to a Au-top-metalized $\mathrm{Cu}$ electrode spacer with a size of $1 \mathrm{~L} \times 1 \mathrm{~W} \times 0.4 \mathrm{~T}$ (in millimeter). The $\mathrm{Cu}$ electrode spacer was fabricated on the $\mathrm{Cu} / \mathrm{Ni}(\mathrm{P}) / \mathrm{Au}-$ metalized $\mathrm{Si}_{3} \mathrm{~N}_{4}$ ceramic substrate with $\mathrm{Au}-12 \mathrm{Ge}$ solder. Figure 1 shows the schematic of the experimental conditions and methods of the electrical test. The anode and the cathode of the electrical power were connected to the anode and cathode of the SiC-SBD, respectively (Fig. 1a). The voltage was applied and increased. The measured $I-V$ curve was the $I_{\mathrm{F}}-V_{\mathrm{F}}$ curve, which gives the on-state resistance (Ron) from the slope of the curve. Reversely, the cathode and anode of the electrical power were connected to the anode and cathode of the SiC-SBD, respectively (Fig. 1b). The measured $I-V$ curve was the $I_{\mathrm{R}}-V_{\mathrm{R}}$ curve, which represents the capability of withstanding the reverse voltage.

\section{Results}

Bonding with Au-20Sn paste

Figure 2 shows the morphology of the SABA after reflow with different solders. Panels a and $b$ of Fig. 2
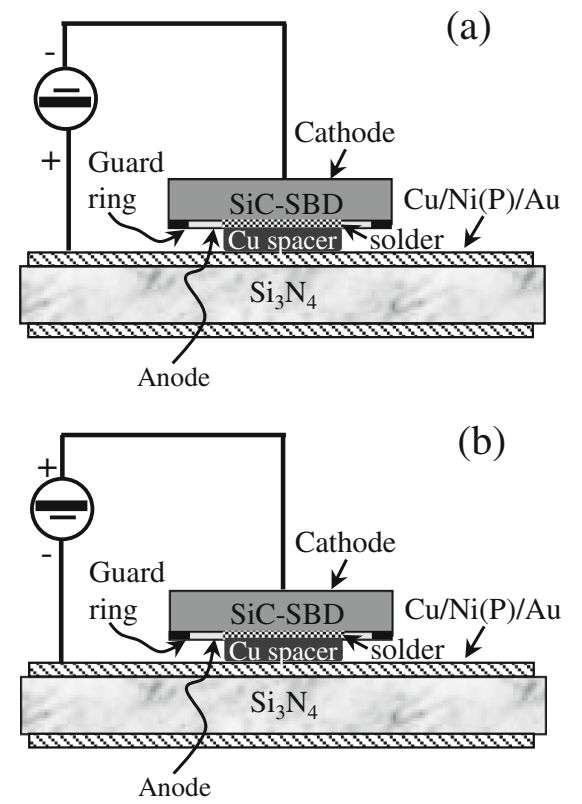

Fig. 1 Schematic of measuring the electrical properties of the bonded SiC-SBD with SABA present the morphology of the SABA after reflow with $\mathrm{Pb}-10 \mathrm{Sn}$ paste at $350{ }^{\circ} \mathrm{C}$ for $200 \mathrm{~s}$ and $\mathrm{Sn}-3.5 \mathrm{Ag}-0.5$ $\mathrm{Cu}$ paste after reflow at $250{ }^{\circ} \mathrm{C}$ for $200 \mathrm{~s}$, respectively. Upon reaching the solidus temperature of the $\mathrm{Pb}-10 \mathrm{Sn}$ solder or the M.P of the $\mathrm{Sn}-3 \mathrm{Ag}-0.5 \mathrm{Cu}$ solder, the solder melted and formed a ball in the Au bump. Then, the solder ball moved freely on the Al electrode, without any bonding to the Al electrode. During reflow, the $\mathrm{Au}$ bump was dissolved into the solder, left a $\mathrm{Au}$ bump's root in the $\mathrm{Al}$ electrode. This means that $\mathrm{Pb}$ $10 \mathrm{Sn}$ and $\mathrm{Sn}-3 \mathrm{Ag}-0.5 \mathrm{Cu}$ solder pastes could not bond the SABA.

Panels $\mathrm{c}$ and $\mathrm{d}$ of Fig. 2 show the morphologies of the $\mathrm{Al}$ electrode without and with a $\mathrm{Au}$ bump after reflow with the $\mathrm{Au}-20 \mathrm{Sn}$ solder at $340{ }^{\circ} \mathrm{C}$ for $60 \mathrm{~s}$, respectively. As shown in Fig. 2c, the Au-20Sn solder does not bond the Au bump-free Al electrode. During reflow, the molten solder formed a metallic ball and randomly moved on the surface of the $\mathrm{Al}$ electrode, without bonding to the $\mathrm{Al}$ electrode. However, for the Al electrode with single Au stud bump in its center, a Au-20Sn metallic ball formed upon the solder melted and was immediately trapped by the Au bump. The soldering initiated at the Au bump and then spreaded on the $\mathrm{Al}$ electrode.

Figure 3 illustrates the shear strength of the Au-20Sn solder on the $\mathrm{Al}$ electrode as a function of number of the Au bumps. The shear strength was calculated through dividing the shear force by the bonding area, which was measured by a digital microscope. Three samples were used for each number of $\mathrm{Au}$ bumps. The shear strength was not significantly affected by the number of Au stud bumps. This is due to, as will be shown in Figs. 4 and 5, the spreading rate of the $\mathrm{Au}-$ $20 \mathrm{Sn}$ solder on the SABA at $340{ }^{\circ} \mathrm{C}$ was high and a $\mathrm{Au}$ bump was sufficient to complete the reaction. The shear strength exceeds $60 \mathrm{MPa}, \sim 10$ times higher than the required strength limit [21].

Figure 4a shows the cross-sectional fracture morphology of the $\mathrm{Al}$ electrode with a Au bump bonded with the Au-20Sn solder. The soldering was carried out at $340{ }^{\circ} \mathrm{C}$ for $60 \mathrm{~s}$. The $\mathrm{Au}$ in the liquid solder reacted with the $\mathrm{Al}$ electrode forming a $\mathrm{Au}_{4} \mathrm{Al}$ intermetallic compound (IMC) at the interface between the solder and the $\mathrm{W}$ layer. The $\mathrm{Au}_{4} \mathrm{Al}$ layer exhibits a columnar structure. Reaction of $\mathrm{Au}$ with $\mathrm{Al}$ resulted in depletion of $\mathrm{Au}$ in the Au-20Sn solder. The AuSn ( $\delta$ phase) in the solder is a hypereutectic phase, formed mainly due to the deviation from the eutectic composition.

Figure $4 \mathrm{~b}$ presents the interfacial morphology of the solder and the $\mathrm{SiC}-\mathrm{SBD}$ after shear test. The $\mathrm{Au}_{4} \mathrm{Al}$ layer was observed at the $\mathrm{Au}-20 \mathrm{Sn} / \mathrm{W}$ interface. $\mathrm{Au}_{4} \mathrm{Al} \mathrm{IMC}$ was also observed at the center of the interface (Fig. 4c). The spreading of the solder on the $\mathrm{Al}$ electrode is determined by the lateral 
Fig. 2 Surficial morphology of the $\mathrm{Al}$ electrode after reflow with different solders: a Pb-10Sn on the SABA after reflow at $350{ }^{\circ} \mathrm{C}$ for $200 \mathrm{~s}$; b Sn-3.5Ag- $0.5 \mathrm{Cu}$ solder on the SABA after reflow at $250{ }^{\circ} \mathrm{C}$ for $200 \mathrm{~s}$; c Au-20Sn solder on the $\mathrm{Al}$ electrode without a Au bump after reflow at $340{ }^{\circ} \mathrm{C}$ for $60 \mathrm{~s}$; d Au-20Sn solder on the SABA after reflow at $340{ }^{\circ} \mathrm{C}$ for $60 \mathrm{~s}$
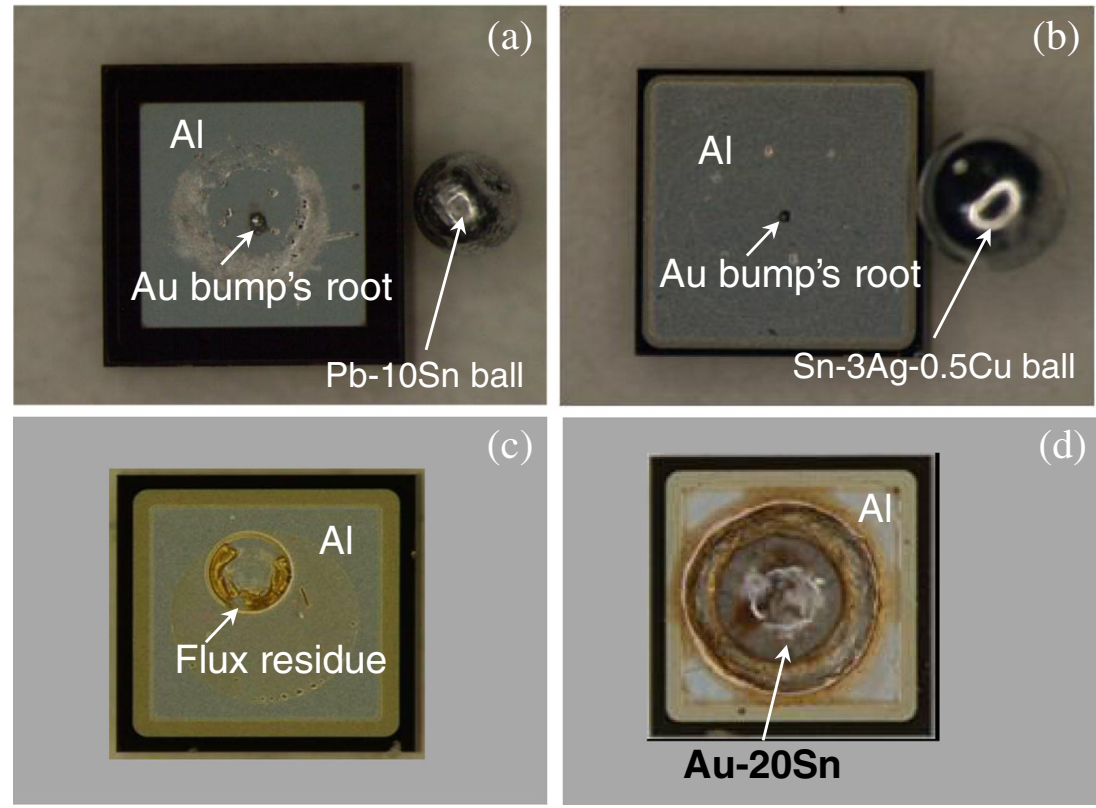

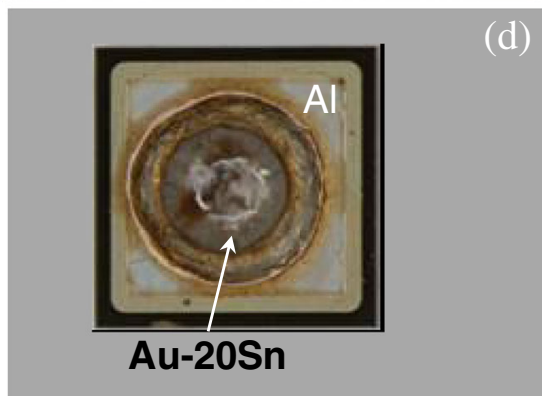

$500 \mu \mathrm{m}$ growth of $\mathrm{Au}_{4} \mathrm{Al}$ layer. Clearly, the soldering of Au-20Sn solder on the $\mathrm{Al}$ electrode featured as reactive wetting.

Figure 5 depicts the interfacial morphology of the Au-20Sn solder and the SABA after shear test. The size of the $\mathrm{Au}_{4} \mathrm{Al}$ grains was $\sim 1 \mu \mathrm{m}$. The Au-Sn solder, which was identified by $\mathrm{SEM} / \mathrm{EDX}$, was observed in the $\mathrm{Au}_{4} \mathrm{Al}$ grain boundaries.

Variations of the base radius of the $\mathrm{Au}-20 \mathrm{Sn}$ solder ball as a function of reflow time at various temperatures are shown in Fig. 6a. The reactive spreading rate generally exhibits a linear law [20, 22-24]. The solid lines plotted in the figure are the least-square fits of the data. The spreading rates are revealed in the slope of the lines. The spreading rate increases rapidly with increasing soldering temperature. This indicates that the

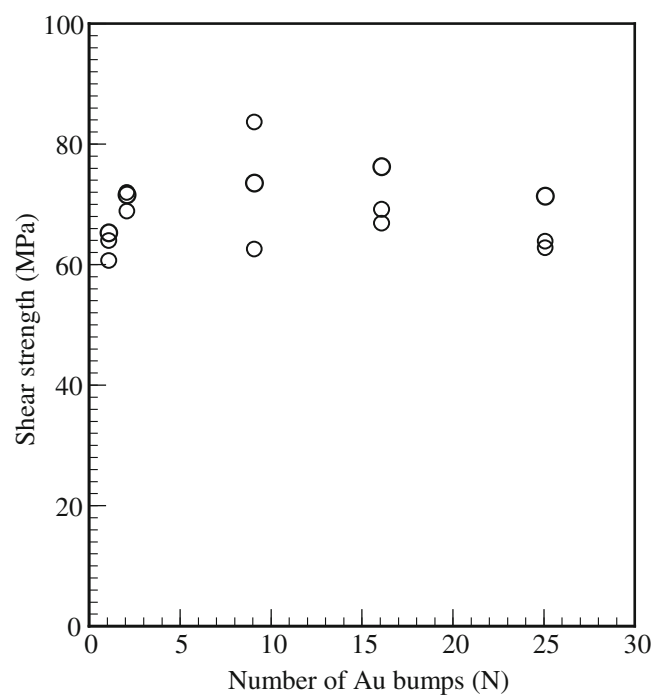

Fig. 3 Shear strength of the Au-20Sn solder on the SABA as a function of number of Au bumps. Reflow was conducted at $340{ }^{\circ} \mathrm{C}$ for $60 \mathrm{~s}$ spreading of $\mathrm{Au}-20 \mathrm{Sn}$ solder on the SABA is a thermally activated process. The spreading rate for a reactive wetting is described as Eq. (1) [20, 24].

$d R / d t=k \exp (-Q / R * T)$

Where $d R / d t$ is the spreading rate, $k$ is a constant, $Q$ is the activation energy for the spreading, $R^{*}$ is the universal gas constant, $T$ is the temperature in Kelvin. The spreading rates were plotted with $1 / T$, as shown in Fig. $6 \mathrm{~b}$. The soldering temperature has strong effect on the spreading rate. The spreading rate increased approximate 1 order magnitude when the soldering temperature was increased from 320 to $340{ }^{\circ} \mathrm{C}$. At a lower reflow temperature as shown in our previous work [25], because of the low reaction rate of $\mathrm{Au}-20 \mathrm{Sn}$ solder with Al electrode, several hundreds of Au bumps were necessary to reach a high bond strength. This was cost-ineffective. At a higher reflow temperature as described in this work, a single Au bump was enough to reach a high bond strength due to the high reaction rate between the solder and the Al electrode.

The activation energy was calculated by fitting the data in Fig. 6b with Eq. (1). The activation energy is $Q=159 \mathrm{~kJ} / \mathrm{mol}$. The spreading rate for Au-20Sn solder on the Al electrode can be expressed as Eq. (2) based the data in Fig. 6b, with a unit of meter/second.

$d R / d t=1.81 E+8 \exp (-19190 / T)$

Bonding with $\mathrm{Au}-12 \mathrm{Ge}$ paste

Figure 7 presents the SEM micrograph of a cross section perpendicular to the interface of the $\mathrm{Au}-12 \mathrm{Ge}$ solder on the 

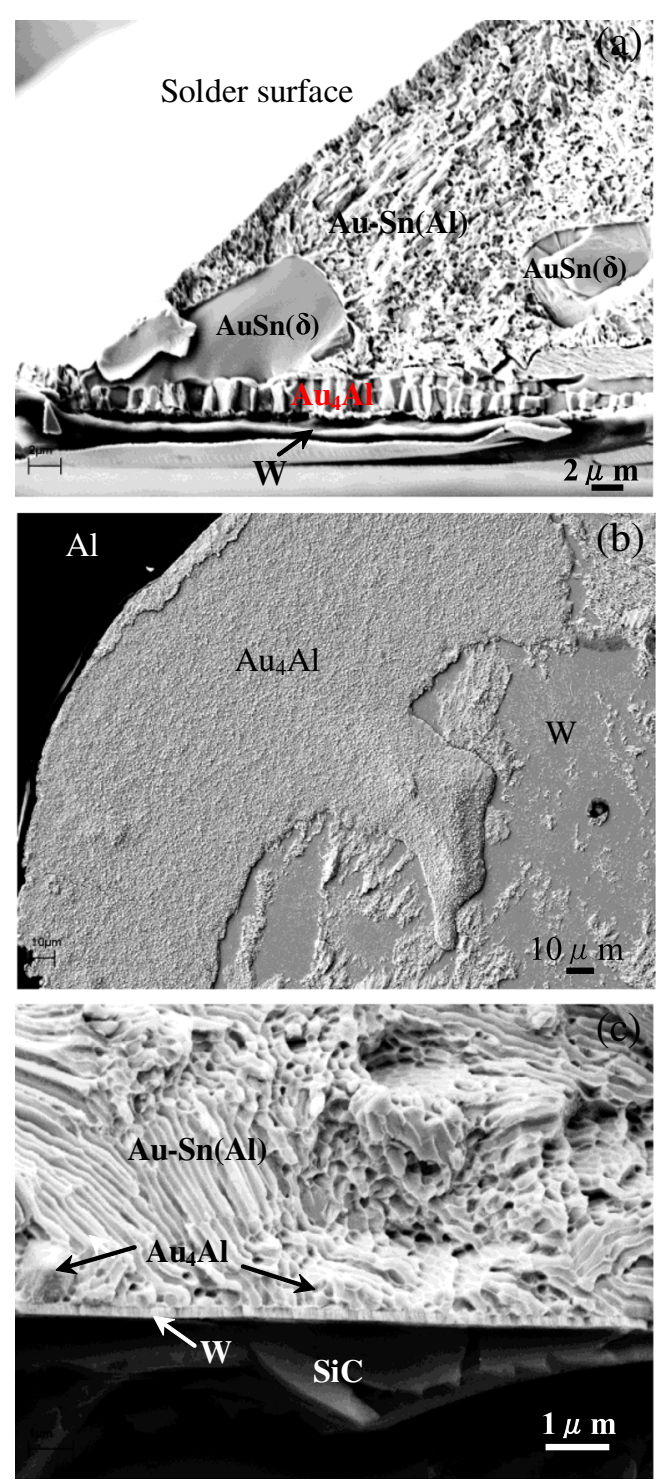

Fig. 4 SEM micrographs of the Au-20Sn solder on the SABA reflowed at $340{ }^{\circ} \mathrm{C}$ for $60 \mathrm{~s}$. a Cross-sectional morphology with fracture of the front of the bond. $\mathbf{b}$ Interfacial morphology after shear test showing the formation of $\mathrm{Au}_{4} \mathrm{Al} \mathrm{IMC}$ at the interface of $\mathrm{Au}-20 \mathrm{Sn} / \mathrm{W}$ layer. c Crosssectional morphology with fracture in the center of the interface

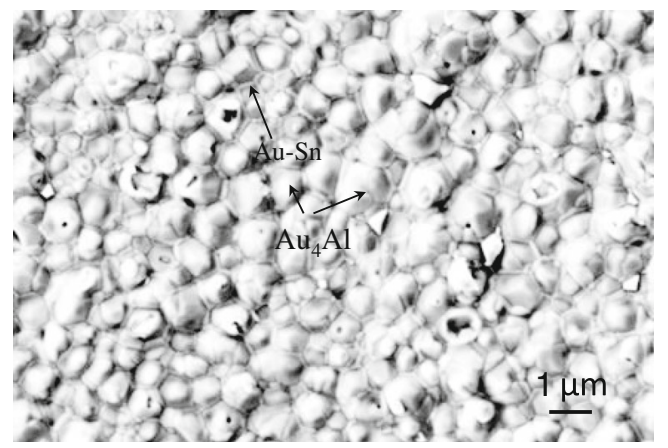

Fig. 5 Magnification of the interfacial morphology of the Au-20Sn solder and the $\mathrm{Au}_{4} \mathrm{Al}$ IMC after shear test
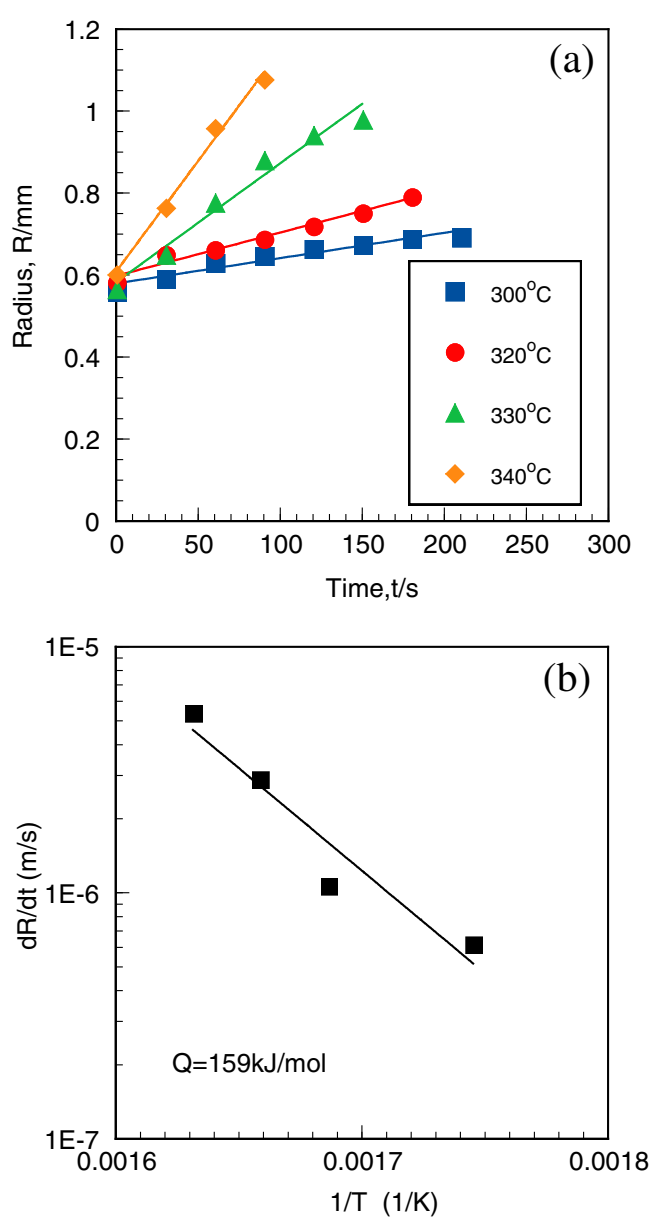

Fig. 6 a Spreading kinetics of the Au-20Sn solder on the SABA at different temperatures. Solder mass, $4 \mathrm{mg}$. b Plot of spreading rate versus $1 / T$ for the isothermal spreading of $\mathrm{Au}-20 \mathrm{Sn}$ solder on the SABA

SABA cooled from 430 to $25^{\circ} \mathrm{C}$. The Au- 12 Ge alloy could well bond the $\mathrm{Al}$ electrode. The $\mathrm{Au}-12 \mathrm{Ge}$ solder joined the $\mathrm{W}$ layer of the SiC-SBD after reflow. EDX analysis in the outlined area with dash lines in Fig. 7 reveals that the composition of the Au-Ge solder was 33Au-67Ge-5Al (at.\%). This means that $\mathrm{Al}$ was dissolved into the $\mathrm{Au}-\mathrm{Ge}$ solder after reflow.

Figure 8 illustrates the elemental mapping of $\mathrm{Au}, \mathrm{Ge}$, and $\mathrm{Al}$ in the fractured surface of SABA after shear test. Al was detected in the Au-Ge solder. This indicates that $\mathrm{Al}$ dissolved into the Au-Ge solder during reflow and dispersed in both the Au-rich phase and the Ge-rich phase after solidification.

Figure 9 shows the SEM micrograph of the interfacial morphology of the SABA after shear test. At the interface of the Au-12Ge solder and SABA, the specimen fractured in the $\mathrm{Au}-\mathrm{Ge}(\mathrm{Al})$ solder near the $\mathrm{W}$ diffusion barrier.

Figure 10 depicts the shear strength of the SiC-SBD bonded on the $\mathrm{Cu} / \mathrm{Ni}(\mathrm{P})$-metalized $\mathrm{Si}_{3} \mathrm{~N}_{4}$ substrate with $\mathrm{Au}-12 \mathrm{Ge}$ solder as a function of number of the Au bumps. The shear strength exhibits a value beyond $\sim 50 \mathrm{MPa}$. The larger scatter of the shear strength may be due to the fact that some chips 


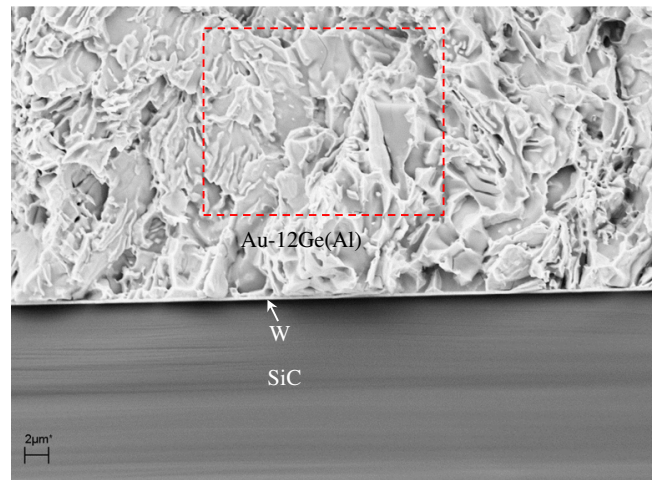

Fig. 7 SEM micrograph of a cross-sectional fractured morphology of the $\mathrm{Au}-12 \mathrm{Ge}$ solder on the SABA cooled from 430 to $25^{\circ} \mathrm{C}$

were destroyed during shear test which resulted in low shear strength. Similar to the bond with the Au-20Sn solder on the SABA, the bond strength of the Au- $12 \mathrm{Ge}$ solder on the SABA was not significantly affected by the number of Au bumps. This is due to, as shown in Figs. 8 and 9, the reaction between the $\mathrm{Au}-12 \mathrm{Ge}$ solder and the $\mathrm{Al}$ electrode initiated at the $\mathrm{Au}$ bump during reflow, and a Au bump was sufficient to complete the reaction at a higher reflow temperature.

\section{Bonding with flux-free solder Au-20Sn and Au-12Ge}

To confirm the fact that the bond of the SABA with Au-based solders is realized by the reaction of the $\mathrm{Au}$ in the Au-based solder rather than the flux in the paste, the SABA was bonded with the Au-20Sn and Au-12Ge sheets in the vacuum reflow system, respectively. No flux was used. Figure 11a shows the surficial morphology of the wetting front of the Au-20Sn solder sheet after reflow at $350{ }^{\circ} \mathrm{C}$ in $\mathrm{N}_{2}$ for $120 \mathrm{~s}$. The solder

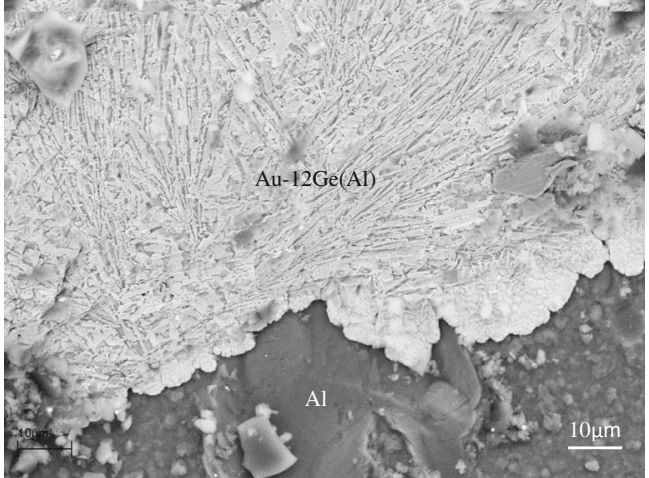

Fig. 9 SEM micrograph of the surficial morphology of the SABA after shear test

bonded the $\mathrm{Al}$ electrode well. EDX analysis in the surface of the solder reveals that the solder has a composition of $\mathrm{Au}$ 25Sn-9Al (at.\%). Since the solder, as shown in Fig. 11b, is $\sim 5 \mu \mathrm{m}$ thick and the EDX analytical depth is $\sim 2 \mu \mathrm{m}$, the detected $\mathrm{Al}$ was from the solder. This indicates that $\mathrm{Al}$ dissolved into the solder. Figure 11b shows the cross-sectional morphology of the Au-bumped Al electrode reflowed with the $\mathrm{Au}-20 \mathrm{Sn}$ solder at $350{ }^{\circ} \mathrm{C}$ for $120 \mathrm{~s}$. The cross-sectional morphology is similar to that of the SABA bonded with the Au-20Sn paste (Fig. 4a). Al dissolved into the Au-20Sn solder to form a $\mathrm{Au}-\mathrm{Sn}(\mathrm{Al})$ solder. $\mathrm{Au}_{4} \mathrm{Al}$ was detected with $\mathrm{SEM} /$ EDX at the interface between the solder and the $\mathrm{W}$ diffusion barrier. This indicates that the bonding of the solder to the $\mathrm{Al}$ electrode was attributed to the alloying effect of the $\mathrm{Au}-20 \mathrm{Sn}$ solder rather than the flux.

Figure 12a shows the fracture morphology of the wetting front of the Au- $12 \mathrm{Ge}$ sheet bonded on a SABA at $430{ }^{\circ} \mathrm{C}$ in $\mathrm{N}_{2}$ for $120 \mathrm{~s}$. No flux was used. Al dissolved into the solder.
Fig. 8 Elemental mappings of $\mathrm{Au}, \mathrm{Ge}$, and $\mathrm{Al}$ in the fractured surface of SABA after shear test. The SABA was bonded with the $\mathrm{Au}-12 \mathrm{Ge}$ solder at $430{ }^{\circ} \mathrm{C}$ for $120 \mathrm{~s}$
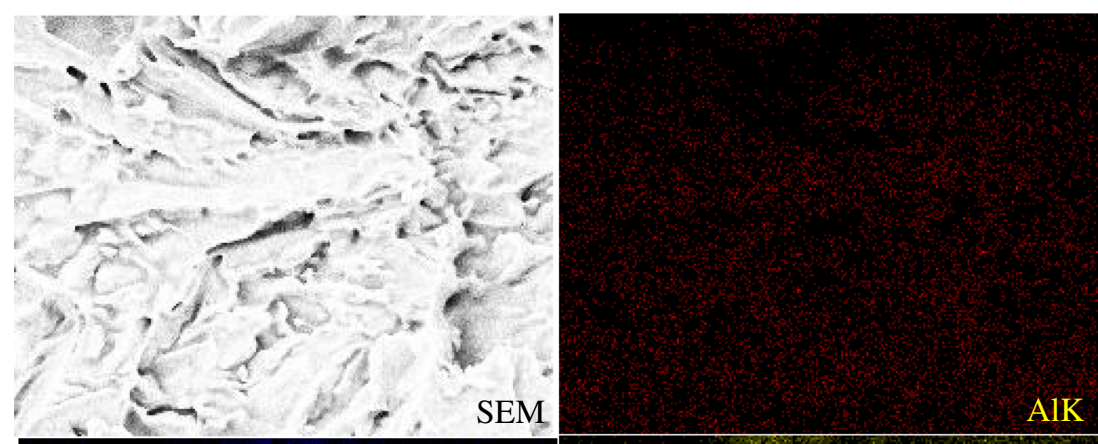


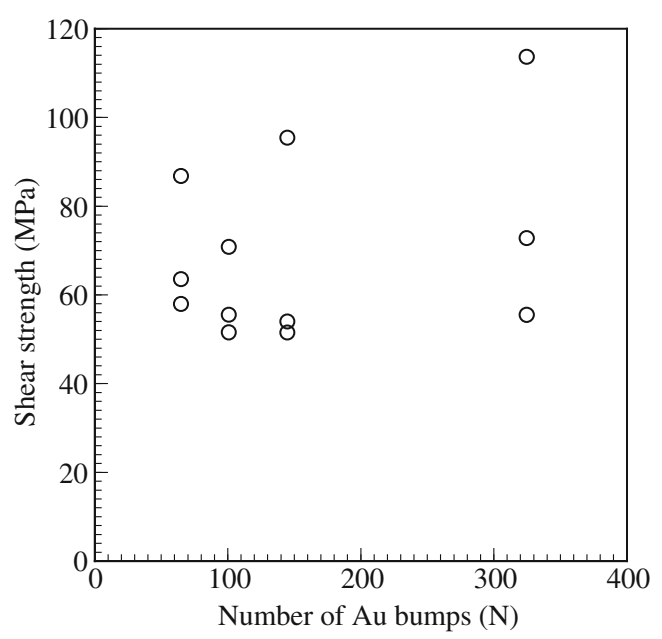

Fig. 10 Shear strength of the $\mathrm{SiC}-\mathrm{SBD}$ bonded on the $\mathrm{Cu} / \mathrm{Ni}(\mathrm{P})$-metalized $\mathrm{Si}_{3} \mathrm{~N}_{4}$ substrate with $\mathrm{Au}-12 \mathrm{Ge}$ solder paste as a function of number of the Au bumps

The solder bonded the W diffusion barrier well. EDX analysis in the fractures surface of the solder reveals that the solder has a composition of $23 \mathrm{Au}-63 \mathrm{Ge}-14 \mathrm{Al}$ (at.\%). Figure $12 \mathrm{~b}$ shows the EDX spectra of the outlined area with dash lines in Fig. 12a. An Al spectrum was clearly detected in addition to $\mathrm{Au}$ and Ge spectra.

These results reveal that the reaction of $\mathrm{Au}$ in the Au-based solder with the Au-bumped Al is responsible for the wettability.

\section{Electrical characteristics}

The SiC-SBDs handle the power energy by having the current flow from the anode to the cathode while blocking it from the cathode to the anode. The electrical characteristics of SiCSBD are characterized by $I_{\mathrm{F}}-V_{\mathrm{F}}$ and $I_{\mathrm{R}}-V_{\mathrm{R}}$ curves. A guard ring on the periphery of the anode of the SiC-SBD is needed for improving the blocking voltage [26]. Hence, to protect the guard ring of the device, space between the guard ring and substrate should be prepared. The Au-top-metalized Cu electrode spacer on the metallic layer of the substrate could meet this requirement. Figure 13 shows the optical morphology of the substrate with a $\mathrm{Cu}$ electrode spacer on the $\mathrm{Cu} / \mathrm{Ni}(\mathrm{P}) / \mathrm{Au}-$ metalized $\mathrm{Si}_{3} \mathrm{~N}_{4}$ ceramic substrate for bonding the $\mathrm{SABA}$. The $\mathrm{Cu}$ electrode was bonded to the metallic layer of the substrate with $\mathrm{Au}-12 \mathrm{Ge}$ solder. A space of $\sim 0.4 \mathrm{~mm}$ between the guard ring of the SiC-SBD and the metallic layer was formed after reflow with the $\mathrm{Au}-20 \mathrm{Sn}$ solder.

Panels a and b of Fig. 14 show the $I_{\mathrm{F}}-V_{\mathrm{F}}$ and $I_{\mathrm{R}}-V_{\mathrm{R}}$ curves of the $\mathrm{SiC}-\mathrm{SBD}$ with its $\mathrm{Al}$ electrode bonded by the $\mathrm{Au}-20 \mathrm{Sn}$ solder on a $\mathrm{Cu} / \mathrm{Ni}(\mathrm{P}) / \mathrm{Au}$-metalized $\mathrm{Si}_{3} \mathrm{~N}_{4}$ substrate, respectively. The space between the guard ring and the substrate was filled with silicon epoxy underfill. Very little change was observed in the $I_{\mathrm{F}}-V_{\mathrm{F}}$ curves before and after soldering the SABA (Fig. 14a). The leakage current was very low, $<9 \mu \mathrm{A}$

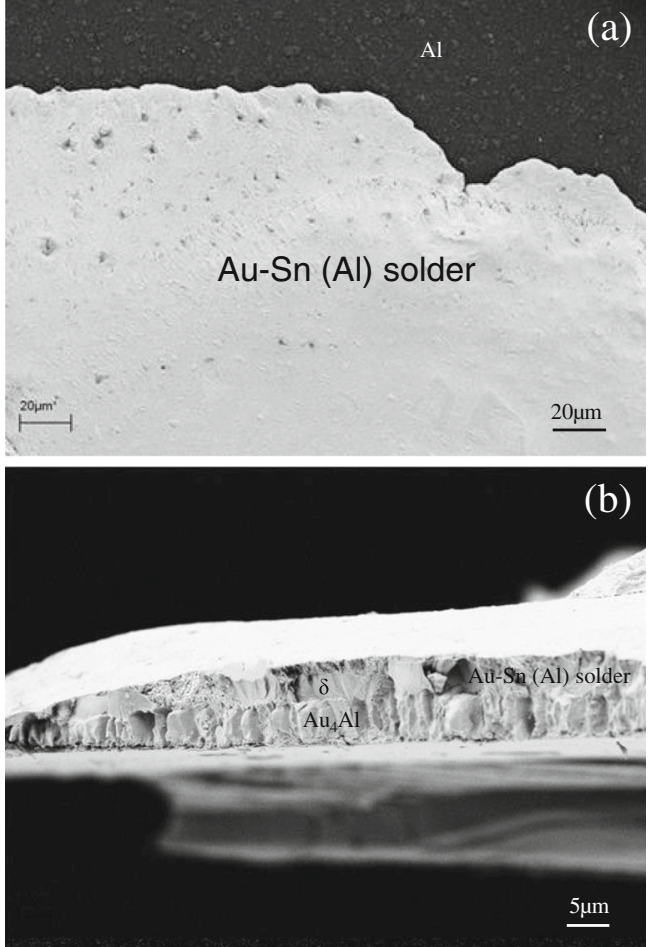

Fig. 11 a Surficial morphology of the wetting front of the Au-20Sn solder sheet and $\mathbf{b}$ cross-sectional morphology of the Au-bumped Al electrode reflowed with the $\mathrm{Au}-20 \mathrm{Sn}$ solder sheet at $350{ }^{\circ} \mathrm{C}$ for $120 \mathrm{~s}$

even at 1,200 V (Fig. 14b). This means that the SiC-SBD had high blocking voltage after its $\mathrm{Al}$ electrode was soldered to a

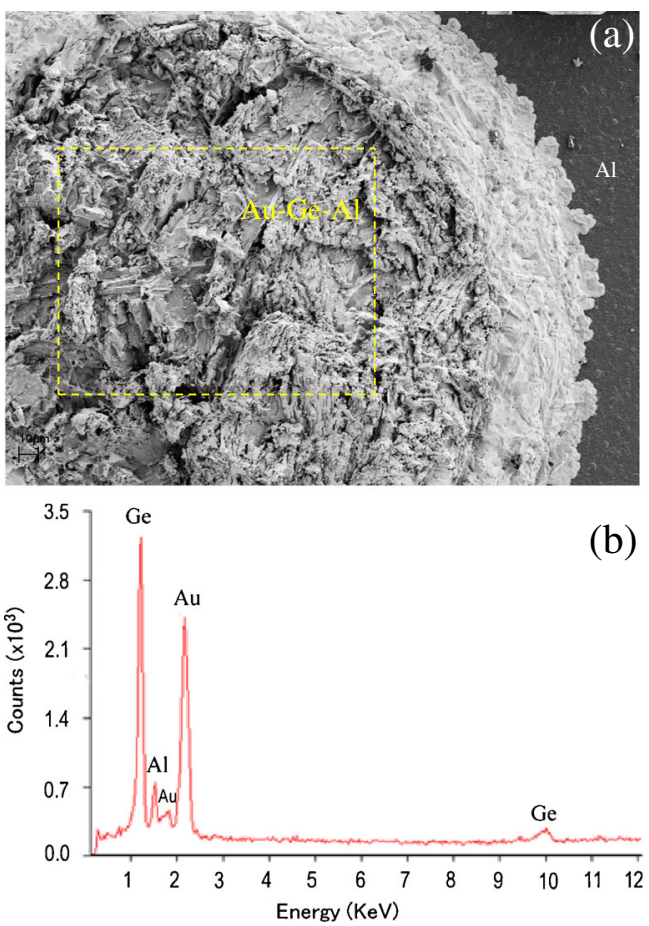

Fig. 12 a Fracture morphology of the Au-12Ge solder sheet bonded on the Au-bumped $\mathrm{Al}$ electrode without a flux. b X-ray spectra of the fractured solder 


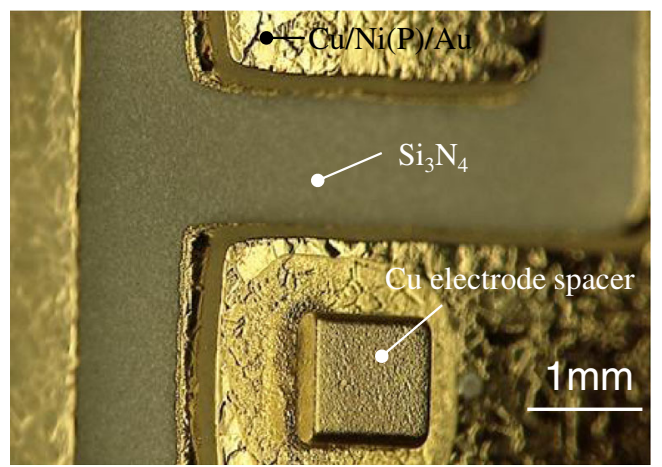

Fig. 13 Optical morphology of the substrate with a $\mathrm{Cu}$ electrode spacer on the $\mathrm{Cu} / \mathrm{Ni}(\mathrm{P}) / \mathrm{Au}$-metalized $\mathrm{Si}_{3} \mathrm{~N}_{4}$ ceramic substrate for bonding the SABA. The image was taken by tilting the sample $27^{\circ}$ from the horizontal level to show the three-dimensional shape of the $\mathrm{Cu}$ electrode spacer

substrate with a $\mathrm{Cu}$ electrode spacer. These results reveal that little electrical characteristics of the SiC-SBD changed after its $\mathrm{Al}$ electrode was bonded to a substrate using this technology.

The SABA was also bonded to the $\mathrm{Cu}$ electrode spacer which had already been bonded to the $\mathrm{Cu} / \mathrm{Ni}(\mathrm{P}) / \mathrm{Au}$-metalized
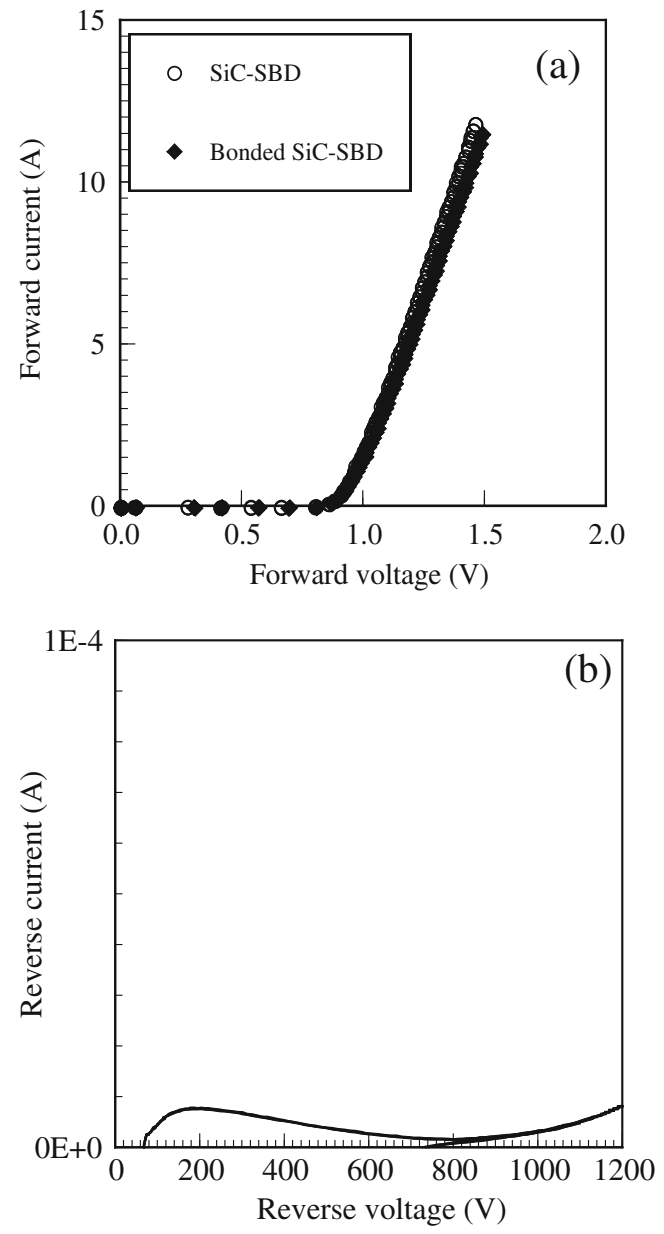

Fig. 14 Electrical characteristics of the SiC-SBD before and after soldering with the Au-20Sn solder. a Forward current-forward voltage curves before and after soldering the $\mathrm{Al}$ electrode. b Reverse currentreverse voltage curves after reflow

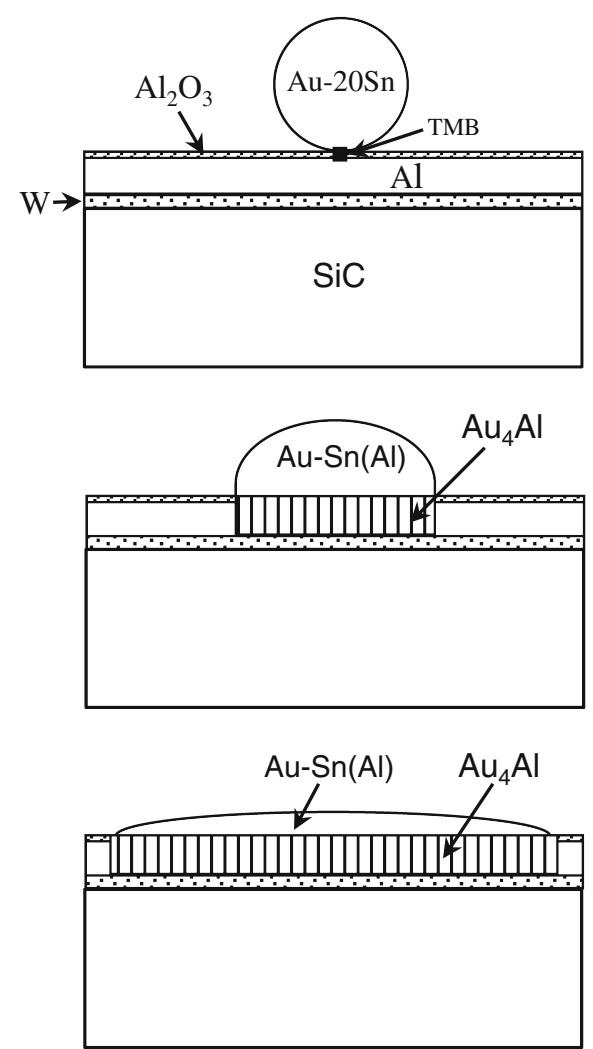

(a)

(b)

(c)

Fig. 15 Schematic of the reactive wetting of the Au-based solder on the Al electrode. a Capture of the solder ball by a TMB. $\mathbf{b}$ Reaction between the solder and the Al electrode initiate at the TMB. c Reactive wetting proceed

$\mathrm{Si}_{3} \mathrm{~N}_{4}$ substrate with the $\mathrm{Au}-12 \mathrm{Ge}$ solder. The space between the gard ring and the substrate was also filled with silicon epoxy filler. As the case of Au-20Sn bonded SABA, very little change in the $I_{\mathrm{F}}-V_{\mathrm{F}}$ curve was observed. The Ron changed from the 50.2 to $50.5 \mathrm{~m} \Omega$. The leakage current measured from the $I_{\mathrm{R}}-V_{\mathrm{R}}$ curve at $1,200 \mathrm{~V}$ was very low, $\sim 3 \mu \mathrm{A}$. Hence, it can be established that very little change occurred after the SABA of the SiC-SBD was bonded to a substrate with a $\mathrm{Cu}$ electrode spacer with the Au-12Ge solder, as the case of the $\mathrm{Au}-20 \mathrm{Sn}$ bonded SABA.

\section{Discussion}

The Pb-based solder was unable to bond the SABA. This is due to the fact that this solder has less reactivity with Al. The eutectic $\mathrm{Al}-\mathrm{Pb}-\mathrm{Sn}$ only contains $0.08 \mathrm{wt} \% \mathrm{Al}$ [27]. That is to say, in view of thermodynamics, very little amount of $\mathrm{Al}$ is dissolved in the $\mathrm{Pb}-\mathrm{Sn}$ solder. Hence, the $\mathrm{Pb}$-Sn solder almost did not react with the $\mathrm{Al}$ electrode at the Au bump. As a result, the $\mathrm{Pb}-10 \mathrm{wt} \% \mathrm{Sn}$ solder did not bond the Al electrode. For the Sn-based solder bonding on the SABA, as neither Sn-Al IMC nor $\mathrm{Sn}-\mathrm{Al}$ solubility exists at room temperature in the $\mathrm{Al}-\mathrm{Sn}$ binary phase diagram [28], the Sn-based solder is difficult to 
react with the $\mathrm{Al}$ electrode. Although $\mathrm{Al}$ can react with $\mathrm{Ag}$, the activity of $\mathrm{Ag}$ in the solder was not enough to form a $\mathrm{Ag}$ - $\mathrm{Al}$ intermetallic or to form a $\mathrm{Ag}$ solid solution under the reflow conditions. Hence, the Sn-based solder is hard to be used to bond the SABA.

Unlike the Pb-based and Sn-based solders, $\mathrm{Au}$ in the Aubased solders can react with $\mathrm{Al}$ to form the solid solution and the Au-Al IMCs. Figure 15 shows the schematic of the reactive wetting of the $\mathrm{Au}-20 \mathrm{Sn}$ solder on an $\mathrm{Al}$ electrode with a tinny metal block (TMB) such as a Au bump. During reflow, a solder ball forms and immediately fixed by the wettable TMB (Fig. 15a). Since the aluminum oxide film is disrupted at the $\mathrm{TMB}$, reaction between the liquid $\mathrm{Au}$ in the molten solder and solid-state Al becomes possible. The reaction initiates at the TMB. The thin aluminum oxide film is destroyed with the progress of the reaction. A continuous $\mathrm{Au}_{4} \mathrm{Al}$ IMC layer forms at the interface between the solder and the W layer (Fig. 15b). With reactive spreading of the Au-based solder on the $\mathrm{Al}$ electrode, the device is bonded by the Au-based solder (Fig. 15c). The wetting behavior of the Au-20Sn solder on the SABA is similar to that of spreading of $\mathrm{Cu}-40$ at. $\%$ Si alloy on vitreous carbon [20]. In this system, wetting is prompted by the formation of a continuous $\mathrm{Au}_{4} \mathrm{Al}$ layer with an active energy of $159 \mathrm{~kJ} / \mathrm{mol}$.

During reflow of Au- $12 \mathrm{Ge}$ solder on the SABA, the reaction of liquid $\mathrm{Au}-\mathrm{Ge}$ solder with $\mathrm{Al}$ initiated at the Au bump. With increasing reflow time, the $\mathrm{Al}$ dissolved into the Au-Ge solder forming a ternary alloy of AuGe-Al. The Au-Ge-Al solder wetted the $\mathrm{W}$ diffusion barrier of the SiC-SBD. After solidification, the solder bonded the $\mathrm{W}$ diffusion barrier, resulting in bond of the SiC-SBD by the Au-Ge-Al solder.

To insure the high blocking voltage of the SiC-SBD, a space between the guard ring of the device and the substrate are needed. Since wetting of the solder on the SABA initiate at the TMB and the solder spreads with a spreading rate as described in Eq. (2), the soldering area can be controlled by the reflow temperature and time. Hence, a reflow temperature and time can be set to allow the solder unable to reach the guard ring. On the other hand, a $\mathrm{Cu}$ electrode spacer on the substrate with a size smaller than the SABA can make sure a space between the SABA and the substrate.

\section{Conclusions}

The non-solderable Al electrode can be soldered by the Aubased solders along with fabricating a TMB in the Al electrode. Soldering initiated at the TMB (e.g., a Au bump) and a reactive spreading pervaded on the $\mathrm{Al}$ electrode. A continuous $\mathrm{Au}_{4} \mathrm{Al}$ intermetallic compound layer formed at the bonding interface by reaction of the liquid $\mathrm{Au}$ from the $\mathrm{Au}-20 \mathrm{Sn}$ solder with the solid Al electrode. The activation energy of the Au-
20Sn soldering the single Au-bumped $\mathrm{Al}$ electrode is $Q=$ $159 \mathrm{~kJ} / \mathrm{mol}$. The shear strength exceeded $60 \mathrm{MPa}, \sim 10$ times higher than the required strength limit. Similarly, the Au- $12 \mathrm{Ge}$ solder reacted with the $\mathrm{Al}$ electrode resulting in a bonding of the Au-12Ge with the SABA. The shear strength of the Al electrode by the $\mathrm{Au}-12 \mathrm{Ge}$ solder was beyond $50 \mathrm{MPa}$. The reaction of $\mathrm{Au}$ in the Au-based solder with the Au-bumped $\mathrm{Al}$ is responsible for the wettability. Little electrical characteristics of the SiC-SBD changed after bonding the $\mathrm{Al}$ electrode using this technology.

Acknowledgments This work was financially supported by the NEDO (New Energy and Industrial Technology Development Organization, Japan) project, Development of Inverter Systems for Power Electronics, and partially supported by the project of Development of the NextGeneration Power Electronics Technology. This research work was mainly conducted in Energy Semiconductor Electronics Research Laboratory of AIST. The authors thank Dr. H. Ohashi, Dr. M. Aoyagi, and Dr. Y. Hayashi for their discussions.

Open Access This article is distributed under the terms of the Creative Commons Attribution License which permits any use, distribution, and reproduction in any medium, provided the original author(s) and the source are credited.

\section{References}

1. Chinthavali M, Ozpineci B, Tolbert LM, Zhang H (2009) Summary of $\mathrm{SiC}$ research for transportation applications at ORNL. Mater Sci Forum 600-603:1239-1242

2. Virshup A, Liu F, Buchholt F, Spetz AL, Porter LM (2011) Improved thermal stability observed in Ni-based ohmic contacts to n-type $\mathrm{SiC}$ for high-temperature applications. J Electron Mater 40:400-405

3. Harman GG (2010) Wire bonding in microelectronics, 3rd edn. McGraw-Hill, New York

4. Li DM, Li Q, Pan F (2008) Improvement in power durability of Al electrode films used in SAW devices by $\mathrm{Zr}$ additive and $\mathrm{Ti}$ underlayer. J Electron Mater 37:180-184

5. Gan CL, Francis C, Chan BL, Hashim U (2013) Extended reliability of gold and copper ball bonds in microelectronic packaging. Gold Bull 46:103-115

6. Xu H, Qin I, Clauberg H, Chylak B, Acoff VL (2013) Behavior of palladium and its impact on intermetallic growth in palladium-coated $\mathrm{Cu}$ wire bonding. Acta Mater 61:79-88

7. Yoon SW, Glover MD, Mantooth HA, Shiozaki K (2013) Reliable and repeatable bonding technology for high temperature automotive power modules for electrified vehicles. J Micromech Microengn 23(1):015017

8. Kit C, Schirmer KC, Rowden B, Mantooth HA, Simon S, Ang SS, Balda JC (2011) Packaging and modeling of SiC power modules. ECS Trans 41:183-188

9. Mozetic M, Zalar A, Cvelbar U, Babic D (2004) AES characterization of thin oxide films growing on $\mathrm{Al}$ foil during oxygen plasma treatment. Interface Anal 36:986-988

10. Campbell T, Kalia PK, Nakano A, Vashishta P, Ogata S, Rodgers S (1999) Dynamics of oxidation of aluminum nanoclusters using variable charge molecular-dynamics simulations on parallel computers. Phys Rev Lett 82:4866-4869 
11. Azumi K, Yugiri T, Seo M, Fujimoto S (2001) Double zincate pretreatment of sputter-deposited Al films. J Electrochem Soc 148: C433-C438. doi:10.1149/1.1370966

12. Lee SK, Lee JH, Kim YH (2007) Nucleation and growth of zinc particles on an aluminum substrate in a zincate process. J Electron Mater 36:1442-1447

13. Koleňák R, Šebo P, Provazník M, Koleňáková M, Ulrich K (2011) Shear strength and wettability of active $\mathrm{Sn} 3.5 \mathrm{Ag} 4 \mathrm{Ti}(\mathrm{Ce}, \mathrm{Ga})$ solder on $\mathrm{Al}_{2} \mathrm{O}_{3}$ ceramics. Mater Des 32:3997-4003

14. Wang WL, Tsai YC (2012) Microstructural characterization and mechanical property of active soldering anodized $6061 \mathrm{Al}$ alloy using $\mathrm{Sn}-3.5 \mathrm{Ag}-x \mathrm{Ti}$ active solders. Mater Charact $68: 42-48$

15. Wang Z, Wang HY, Liu LM (2012) Study on low temperature brazing of magnesium alloy to aluminum alloy using $\mathrm{Sn}-x \mathrm{Zn}$ solders. Mater Des 39:14-19

16. Huang ML, Huang YZ, Ma HT, Zhao J (2011) Mechanical properties and electrochemical corrosion behavior of $\mathrm{Al} / \mathrm{Sn}-9 \mathrm{Zn}-x \mathrm{Ag} / \mathrm{Cu}$ joints. J Electron Mater 40:315-323

17. Movahedi M, Kokabi AH, Hosseini HR (2009) An investigation on the soldering of Al3003/Zn sheets. Mater Charact 60:441-446

18. Tan QB, Deng C, Mao Y, He G (2011) Evolution of primary phases and high-temperature compressive behaviors of as-cast AuSn20 alloys prepared by different solidification pathways. Gold Bull 44:27-35
19. Liu YC, Teo JWR, Tung SK, Lam KH (2008) High-temperature creep and hardness of eutectic $80 \mathrm{Au} / 20 \mathrm{Sn}$ solder. J Alloys Compd 448:340-343

20. Eustathopoulos N, Nicholas MG, Drevet B (1999) Wettability at high temperatures, 1 st edn. Pergamon, Oxford

21. International Standard IEC 60749-19

22. Landry K, Eustathopoulos N (1996) Dynamics of wetting in reactive metal/ceramic systems: linear spreading. Acta Mater 44:3923-3932

23. Eustathopoulos N (1998) Dynamics of wetting in reactive metal ceramic systems. Acta Mater 46:2319-2327

24. Peebles DE, Peebles HC, Ohlhausen JA (1998) Kinetics of the isothermal spreading of tin on the air-passivated copper surface in the absence of a fluxing agent. Colloids Surf A 144:89-114

25. Lang FQ, Hayashi Y, Nakagawa H, Aoyagi M, Ohashi H (2009) A novel three-dimensional packaging method for Al-metalized $\mathrm{SiC}$ power devices. IEEE Trans Adv Packgn 32:773-779

26. Kim SJ, Oh DJ, Yu SJ (2006) Breakdown voltage characteristics of $\mathrm{SiC}$ Schottky Barrier Diode with Aluminum deposition edge termination structure. J Korean Phys Soc 49:S768-S773

27. Kartzmark R (1956) The systems aluminum-lead-tin and aluminum-tin. Thesis of MS degree, Univ Manitoba

28. Okamoto H (2000) Desk handbook phase diagrams for binary alloys. ASM International, Ohio 